\title{
Trading Trees for Concrete Blocks; The Developmental Path in Abokobi in the Ga East Municipality
}

\author{
Saviour Kwaku Tepson Tepe ${ }^{{ }^{*}}$ John Nsaman Mensah ${ }^{2}$ \\ 1* Institute of Statistical, Social and Economic Research, University of Ghana, Ghana \\ 2 University of Arkansas Clinton School of Public Service, Little Rock, USA \\ *E-mail of the corresponding author: tepsondela@gmail.com
}

\begin{abstract}
:
The presence of tree life in the landscape of cities is a promising means to supporting life. In an urban community, many of the social, economic, and environmental problems such as health, water, and air pollution, can be attributed to the consistent imbalance between the natural environment, built and socio-economic environments. This paper examines the challenges and prospects of tree life in the face of urbanisation in Abokobi in the Ga East Municipality. Data was obtained using purposive sampling technique, cluster and systematic random sampling techniques to sample key informant interviewees and 120 property owners for the questionnaire survey. In examining the spatial trends of vegetation cover of the entire Ga East Municipality, the paper employed an ArcGIS 10.1 software. The study found that between the base year 2005 to 2017, the study area had experienced continuous depletion of vegetative cover. This has serious implications on human life and the ecosystem. Again, findings from this paper indicates the presence of existing policies vis-à-vis institutional arrangements governing tree life in the study area but lacks implementation. The paper therefore recommends a participatory planning process as an ideal development pathway for the study area, an all-inclusive review of the land tenure system and the augmentation of institutional coordination in enforcing building protocols.
\end{abstract}

Keywords: tree life, urbanisation, land tenure system, sustainable development, Abokobi, Ga East Municipality, Ghana.

DOI: $10.7176 / \mathrm{JEES} / 10-7-09$

Publication date:July $31^{\text {st }} 2020$

\section{Introduction.}

The study defines urbanisation as the increasing share of urban population growth as against the decreasing rural population growth. Throughout history, urbanisation has become an important global issue especially in the $21^{\text {st }}$ century. Studies show that Africa's urbanisation process has been in sharp contrast to other regions (Hedi Arouri et. al, 2014). This means that, even though the process of urbanisation comes with both positive and negative externalities, Africa as a region has come to grapple more with its gloom-ridden outlook (Ibid).

Despite challenges such as human and infrastructural congestion, waste management difficulties, crime, chronic urban diseases such as cholera, and diarrhea, tree life has recently become a major issue in discussing the harmful effects of urbanisation (Dei, 1992; Mougeot, 2006; Heusinkvelt, 2016).

In this study, tree life refers to "all publicly and privately-owned trees" (Nowak \& Crane 2002). Trees play a vital role in enhancing the quality of life in our environment. Trees also bring color and contrasts to the settings of the environment. Not only do trees have a visual quality, they also enhance the environment by improving air quality acting as natural air filters, removing dust, smoke and fumes from the atmosphere.

Even though tree life in the city constitutes a promising means to support life in a community, many of the social, economic and environmental problems such as land, water and air pollution can be attributed to the consistent imbalance between the natural environment, built and socio-economic environments. Ghana has witnessed urbanisation since the beginning of the $21^{\text {st }}$ century, with a current urban population of 54 percent (GSS, 2014) which is expected to increase in the coming years. However, tree life which provides environmental serenity to urban dwellers is increasingly coming under serious threat from infrastructure development. For example, during construction of new buildings, trees that are not in the actual construction floor areas of the parcel are considered as a hindrance to projects and often cleared.

Some studies suggest urbanisation, particularly, increase in urban population growth as the variable explaining more of the gradual loss of urban trees (Heusinkvelt, 2016; Richards, \& VanWey, 2015). Other studies also attribute the "mindless" felling of urban tress to the interrelated factors of the state's promotion of an export-led development strategy, the intensification of agricultural commercialization, as well as household and group differential and unequal access to land as the precursors (Dei, 1992; Heusinkvelt, 2016). Like many other studies 
conducted worldwide, the Ghana Urban Review report (2015) have indicated that Ghana as a country has experienced massive urbanisation growth since the beginning of the year 2000 (World Bank, 2015). The impact of this urban sprawl has left indelible marks on the country's' environmental health. Many cities in Ghana especially the capital Accra, are beset with copious environmental challenges such as perennial flooding, and urban heat island related issues (Grant and Yankson, 2003; Kim and Baik, 2005; Zhao et al.2006). According to Cui and Shi, (2012) these environmental and ecological effects of urban sprawl have raised great concerns and must be handled delicately with urgency.

According to some scholars, factors such as legal, institutional, economic, and operational systems attached to trees in forest outside human settlement (i.e. reserved and off reserved) are more important as far as tree life is concerned. And this has created the limited attention given to urban forests in Ghana.

Abokobi is a peri-urban area, which serves as a buffer zone absorbing population spillovers from central Accra. This phenomenon has resulted in the need for more housing facilities and land spaces leading to the cutting down of trees. In the words of the Municipal Heath Director, at Ga East Municipal Assembly, "we are cutting down all the trees and replacing them with concretes". The increase in real-estates and quarry activities confirms the current massive extractive experiences of the municipality. The population of the Ga East municipality is estimated at $82 \%$ above the national average of $43.3 \%$ (GSS, 2014). Although it is widely acknowledged that the depletion of the forest and its resources is threatening urban and rural livelihoods, very little attention (if any) has been paid to the prospects and challenges of deforestation taking place in the study area. The question they ask is "Should we live on the trees if we do not clear them for infrastructural development"?

It is against this background that this study seeks to investigate the challenges and prospects of tree life in Abokobi in the Ga East Municipality (GEM) in the Greater Accra region of Ghana, noted for its wide green spaces in Accra. This study specifically investigates trends, residents' perception and attitude towards willingness to pay for conservation of tree life, institutional arrangements and challenges confronting terrestrial ecosystem in the research setting. This study is important such that it would be a great source of information to city planners on the looming effect of population increase on the environment and the need to seek ecological rationality.

\section{Theoretical Rationale}

The Ecological Modernization theory provides the theoretical basis for this study. The basic assumption underpinning this theory is the re-adaptation of economic growth and development. In other words, the need to seek ecological concerns in the quest for economic growth and development (Mol, 1995). This theory took centerstage when market-led approaches were employed as a means for economic growth and development with little attention to its deleterious consequences on the environment. The EM theory calls for the transformation of societal institutions at both micro and macro levels (McEwen, 2013 cited in Jabik \& Bawakyillenuo, 2016). These institutions will eventually help in minimizing the extractive nature of growth and development, hence promoting "ecological rationality" (Mol, 1995). The rapid increase in population growth due to urbanisation in Abokobi demands "ecological rationality". The existing environmental problems of human and infrastructural congestion increase in crime, quarry activities and the "mindless" felling of urban tress demand the need to pay attention to environmentally friendly standards. It is therefore critical to align economic growth and development vis-à-vis infrastructural development to ecological concerns (in this case, tree life) to slow or eradicate the looming danger of ecocide.

\section{Materials and Methods}

The purpose of the study was to examine the challenges and prospects of tree life in the face of urbanisation in Abokobi in the Ga East Municipality. To achieve this purpose, combinations of qualitative and quantitative approaches (case study and survey) were used. The case study was employed to document the opinions of respondents on tress life in the research setting. According to Yin (1994), a case study provides a better approach when a "how" or "why" question is being asked about a contemporary set of events over which the researcher has little control. According to Best and Kahn (1993), descriptive research gives the opportunity to use both quantitative and qualitative data in order to find data and characteristics about the population or phenomenon that is being studied. Moreover, to examine the spatial trends of vegetation cover in Abokobi from 2005 to 2017, the study employed the Normalized Difference Vegetation Index (NDVI). Besides using questionnaires, interviews, and observations, the study also relied on documentation and published works such as MTDP, journals, peer reviewed articles, satellite images from GIS/Remote sensing section of the Department of Geography and Resource Development and some relevant documents of the assembly. 


\subsection{Sampling and Data collection process}

Data for the study was obtained through a survey of landlords/ladies ${ }^{1}$ and some selected key informants including the Municipal Environmental Officer, Works Engineer, Deputy Planning Officer, Town and Country Planning Director, Deputy Director of Agriculture and Chief of Abokobi. Our choice of selection of these informants was based on their expertise and knowledge on the subject matter. Purposive sampling technique was used for sampling key informants. The cluster and systematic random sampling techniques were employed to obtain a sample size of 120 landlords from the target population. The research area was divided into four zones and 30 houses were selected from each zone. Landlords/landladies of every other third house were then selected for the survey.

\subsubsection{Data Processing and Mode of Analysis}

Quantitative data was organized and analysed using the Statistical Package for Social Sciences (SPSS 20V) and STATA/SE 13.1. Descriptive statistics including frequency tables, cross tabulations among other were developed from the quantitative data. The qualitative data derived from recorded interviews were transcribed and analysed using the NVivo software package. The software was used as a data administration and archiving tool for the thematic analysis of the transcribed interviews. ArcGIS software was used to examine the spatial trends of vegetation cover in Abokobi from 2005 to 2015 and 2017. This was done by loading bands 4 and band 3, which are the near infrared and red bands respectively. Calibration was performed on these bands to convert the image from radiance to reflectance. The Map Algebra tool, which contains the raster calculation in ArcGIS, was then used to enter the NDVI expression in this format. NDVI= Float (band 4- Band 3)/ (band $4+$ band 3). After the process was performed, the output NDVI map was produced and the shapefile of the study area was overlaid on the NDVI map.

\subsubsection{Description of study area}

Ga East Municipal Assembly (GEMA) was carved out of the then Ga East District which was established in 2004 by an Act of Parliament (Legislative Instrument 1589) as a district. It was elevated to a municipality in 2008 by LI 1864. In June 2012, the Municipality was split into two; Ga East and La-Nkwantanang Madina Municipalities. According to the Population and Housing Census (2010), the population of the Ga East Municipality is 147,742 representing 3.68 per cent of the population of the Greater Accra Region. Abokobi is peri-urban and the capital of the Ga East Municipality. The settlement was founded in 1854 by missionaries of the "Basler Missionsgesellschaft" (Basel Mission) for Christian refugees, who had left Osu (the former Danish-Accra, around Christiansburg). ${ }^{2}$ Tree life exists mostly in the western outskirts and in the north towards the Aburi hills and consists of dense cluster that grow to an average height of about five meters. However, the presence of tree life which lies to the southern parts of the municipality (Abokobi community), is now threatened due to increase in population growth and other urban related activities hence the focus of this study.

\section{RESULTS}

The following section discusses the findings obtained from both the qualitative and quantitative data. The presentation is organized based on the various themes from the main objectives of the study. The initial section discusses responses from the qualitative data whereas the subsequent section discusses those from the quantitative data.

\subsection{State and Trends}

The first objective of this study was to examine the spatial trends of vegetation cover in Abokobi from 2005 to 2017. A comparison between the base year (2005) and the current year 2017 shows a gradual loss of green vegetation cover to more brown spaces as expressed in the NDVI values $(0.459$ to 0.554$)-(0.247$ to 0.234$)$ for 2005. The current year 2017 experienced a further depletion of green areas in Abokobi which is evident in the values ranging from $(0.160$ to 0.242$)-(-0.196$ to 0.054$)$. This trend of depletion is also confirmed in the qualitative data gathered from the key informants. For instance, these responses were captured from the interviews conducted with the chief of Abokobi and the Municipal Environmental Health Officer:

\footnotetext{
${ }^{1}$ Definition of "Landlords/Landladies in this study is based on landlords/landladies who own and have lived in Abokobi for a minimum of five years.

2 "ABOKOBI GREATER ACCRA REGION". ghana-net.com. Archived from the original on 2 July 2011. Retrieved 30 May 2018.
} 
Figure 1. Map of the Study Area

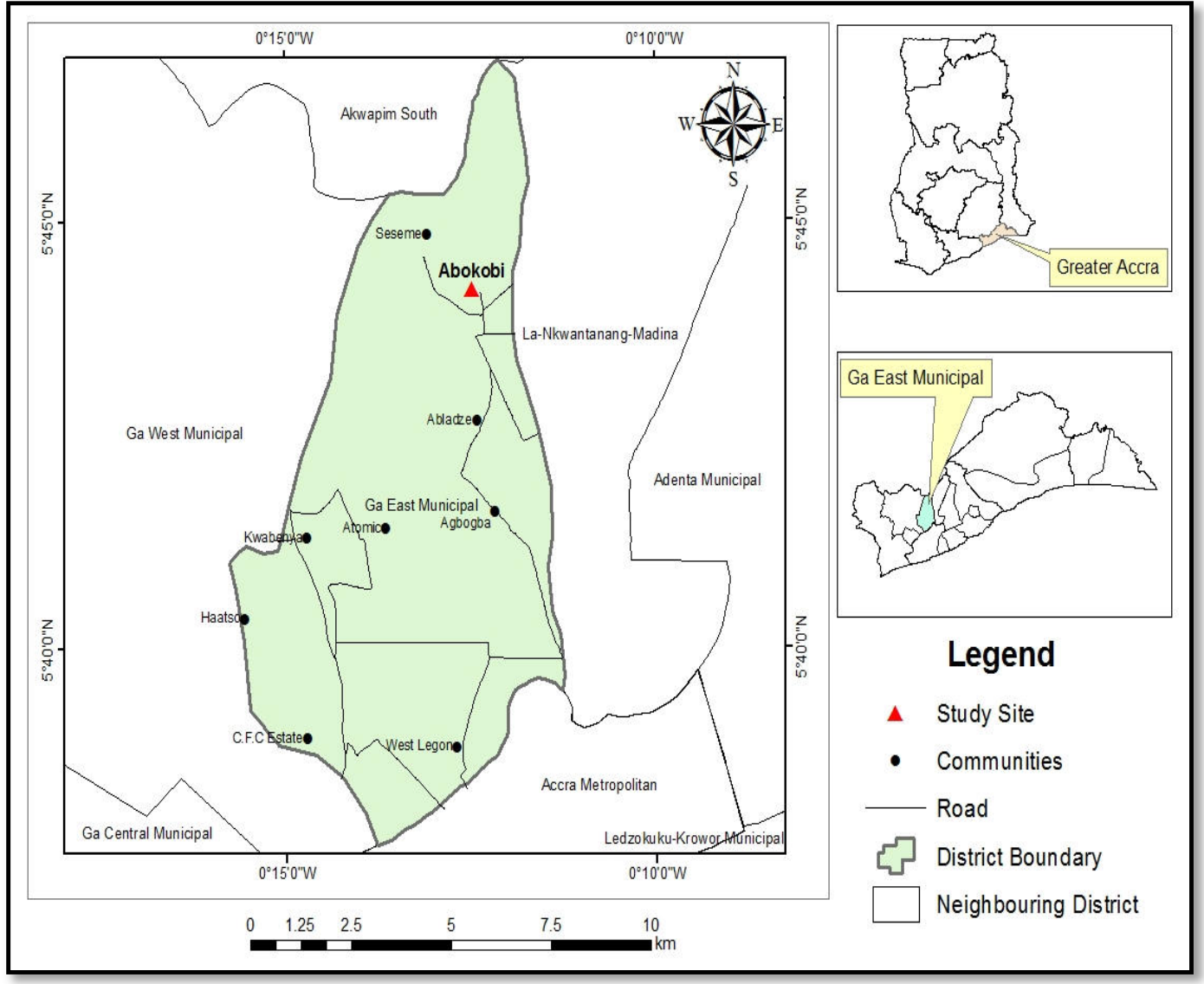

Source: Authors' own construct, 2018

"There is nothing left for us as a forest reserve...... [some time ago] we had trees and big forest. We made there our forest reserve. It is now cleared and there are cement blocks there. They have taken the trees away and planted cement blocks" (Chief of Abokobi)

"As for the vegetation, everyone can see, even if nobody tells you, you can see it. They have removed everything” (Municipal Environmental Health Officer, GEMA)

The findings from the study confirms the report of FAO (2007), who declared that in over a decade and a half, Ghana had lost over $26 \%$ of her forest stock to activities such as mining, wood harvesting, bushfires, infrastructural development. 

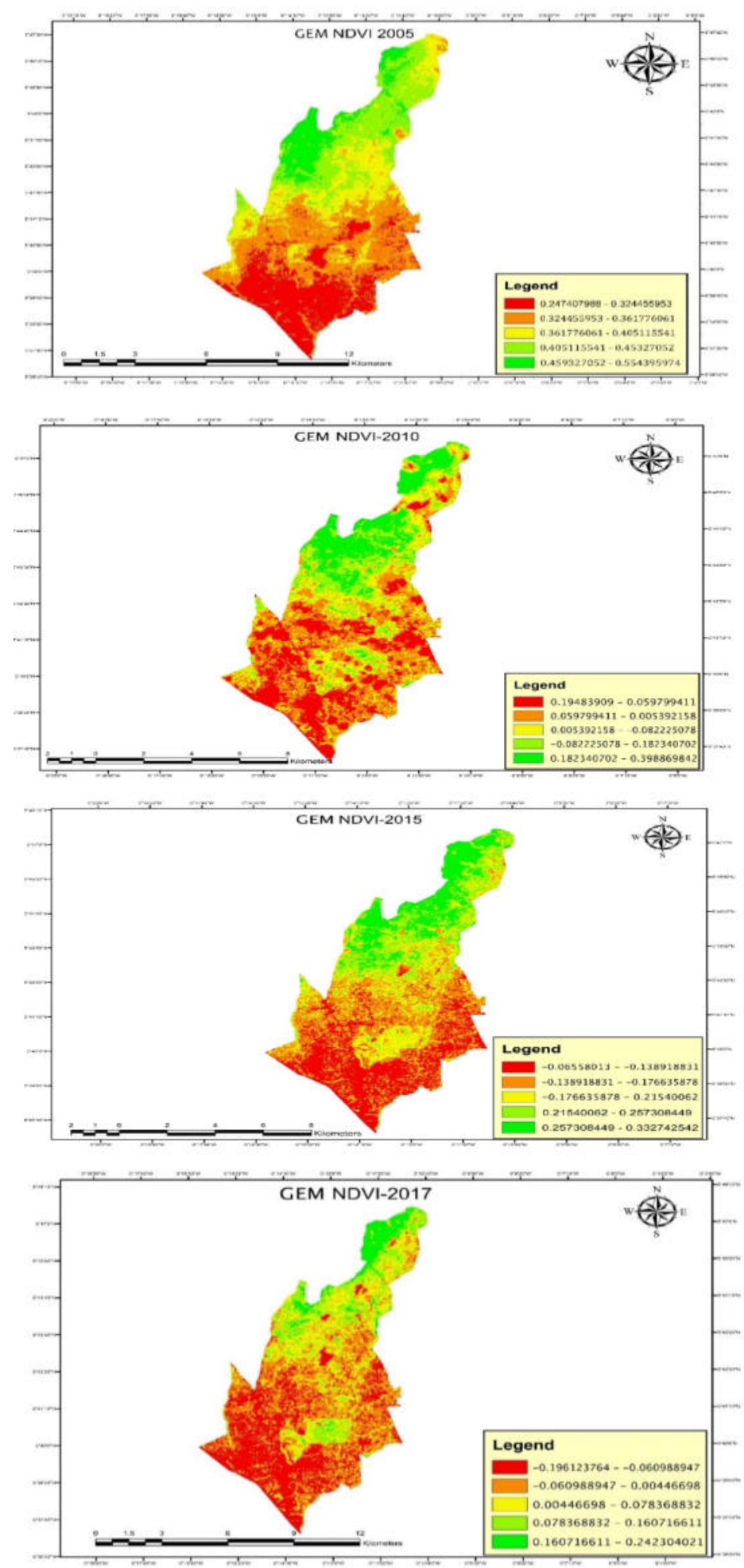

Fig 2. Normalized Difference Vegetation Index (NDVI) of Abokobi - 2005 to $2017^{3}$

${ }^{3}$ Source: GIS/Remote sensing section of the Department of Geography and Resource development, University of Ghana-2018. 


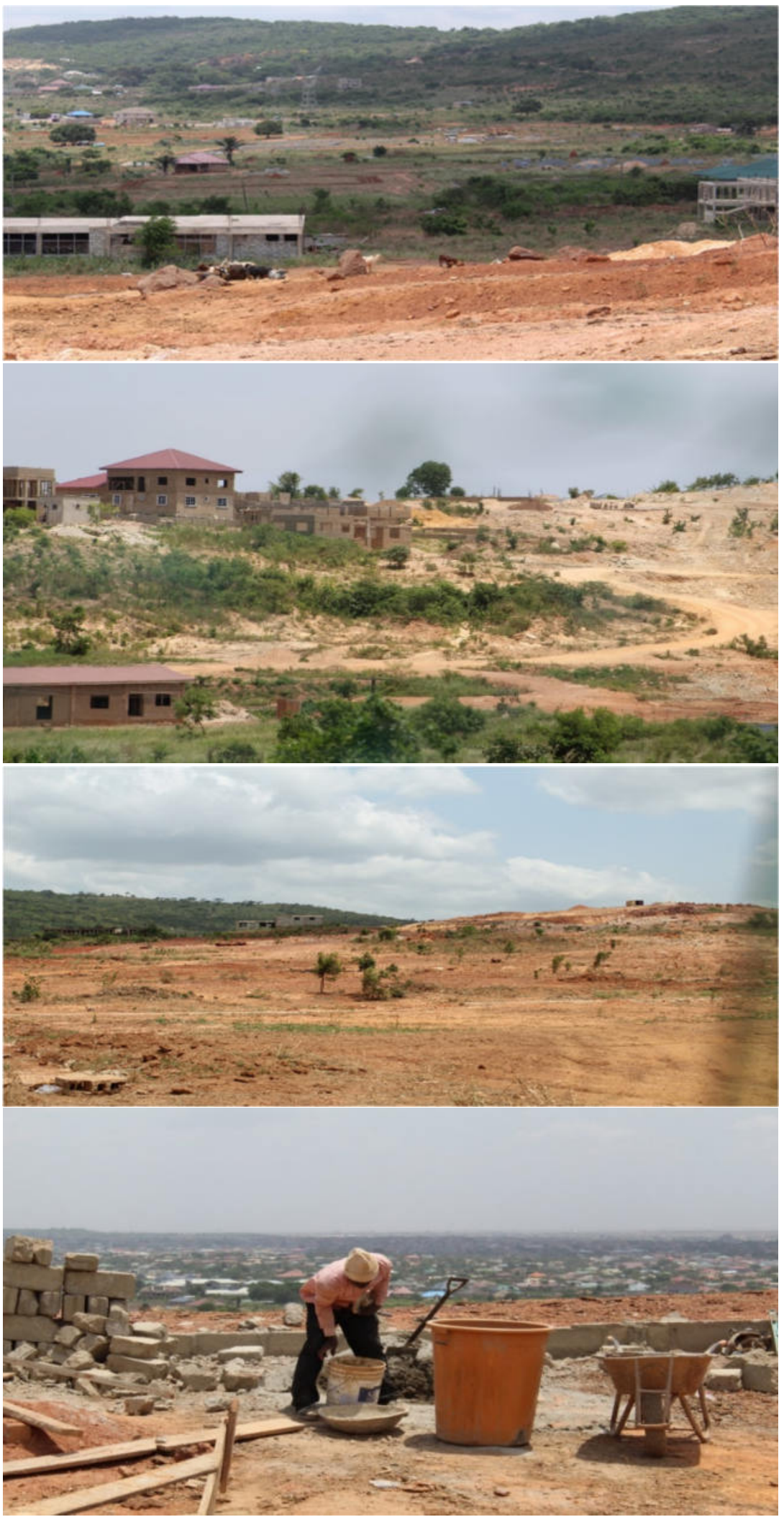

Plate 1. Plates showing depletion of tree life in Abokobi

Source: Authors' Field Data, July 2018. 


\subsubsection{Perception of Tree life}

One objective of this study was to investigate resident's perception about tree life. Findings from the study suggests that tree life in Abokobi have more environmental benefits. According to key informants, trees in the municipality serve as windbreaks during windy or stormy weather. Other views highlighted were that trees provide good ambient air and aids in the formation of rainfall which recharges the water system in Abokobi. They also indicated that trees have aesthetic values which promote green environment and sustainable development. More importantly, some key informants advocated that much attention is paid to the environment in our attempt to develop. One of the key informants had this to say:

"trees serve as windbreaks, so the removal of roof tops or storms that we experience, trees manage all those things" (Municipal Works Engineer)

Moreover, results from the survey confirms the opinions of the key informants. Inhabitants opined that tree life had more environmental benefits. This finding mirrors the work of Dwyer et al.1992; McPherson 1994; Nowak et al.2002, who asserted that trees in urban areas provide urbanites with great environmental benefits by reducing substantial amount of noxious pollutants from the atmosphere.

Table 1. Respondents' knowledge on kind of benefits of trees.

\begin{tabular}{lcccc}
\hline Benefits & $\begin{array}{c}\text { Yes } \\
\text { Frequency }\end{array}$ & $\mathbf{( \% )}$ & $\begin{array}{c}\text { No } \\
\text { Frequency }\end{array}$ & $\mathbf{( \% )}$ \\
\hline Economic & 48 & 40.0 & 72 & 60.0 \\
Social & 69 & 57.5 & 51 & 42.5 \\
Environment & 72 & 60.0 & 48 & 40.0 \\
Cultural & 19 & 15.8 & 101 & 84.2
\end{tabular}

Source: Field Data April 2018

Table 1 illustrates respondents' knowledge on the kinds of benefits trees provide. From the table, 60 per cent of responses affirmed that trees in the study area play environmental functions (health, well-being) whiles about 58 per cent of the responses affirmed that trees have social benefits. The conforming perception about tree life between the inhabitants and key informants may be explained based on their levels of understanding and physical interaction with trees. Residents in the municipality tend to derive environmental utility from trees, which helps to cool the environment, filter the air, break wind, reduce storm runoffs and plays other equally important function. This finding conforms with the work of Summit and McPherson (1998); Nowak et al. (2002) and Schoeneberger, (2009) who stated that trees serve as windbreaks, noise filters as well as provide sink for carbon dioxide.

In order to measure the economic value residents place on tree in Abokobi, the study employed the stated preference model where respondents were asked their willingness to pay for and willingness to accept compensation for the conservation of trees life in Abokobi. The demand and supply curve below explain their responses. 


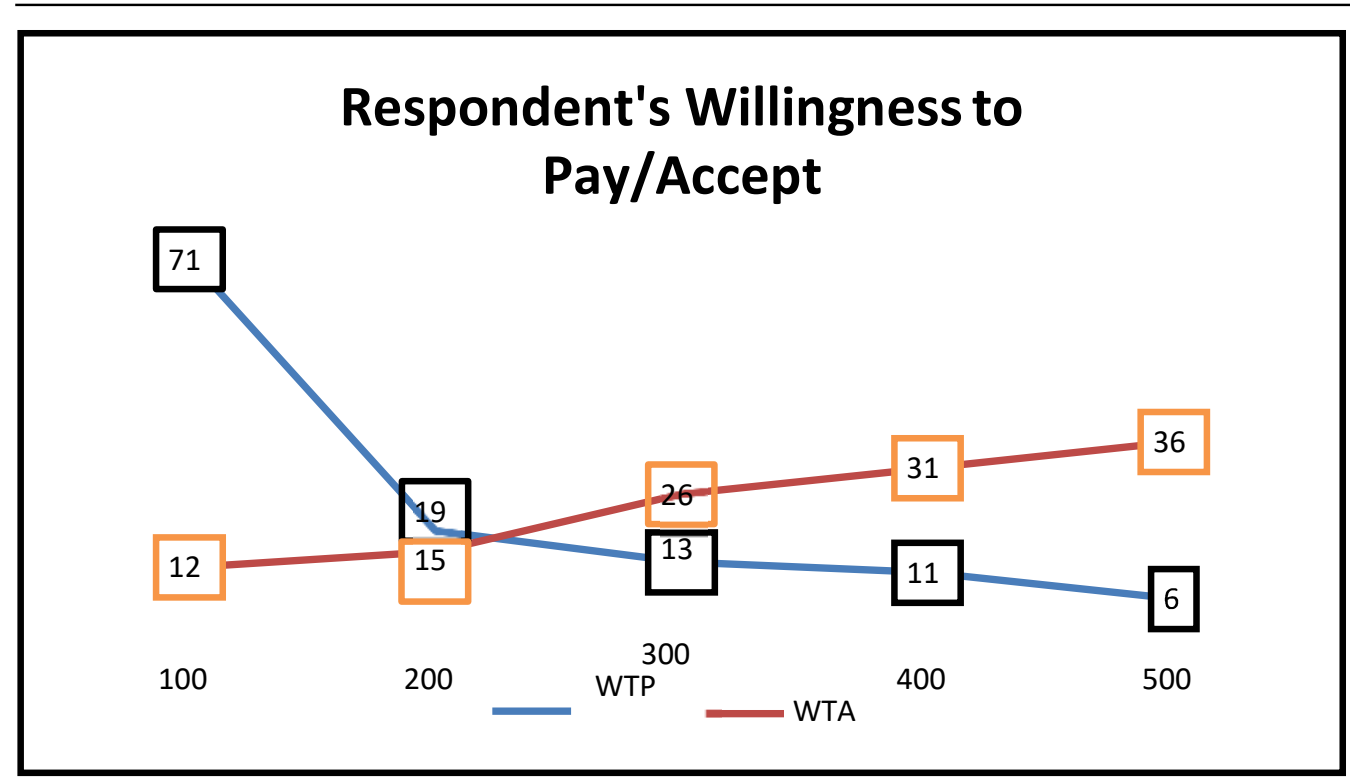

Fig.3 Respondent's willingness to pay/accept compensation

Source: Field Data April 2018

The figure 3 illustrates respondents' willingness to pay for and willingness to accept compensation for the conservation of trees life in Abokobi. The responses were used to generate demand and supply curves. In the case of respondents' willingness to pay for tree life conservation, about 60 per cent of them were willing to pay maximum of GHS 100 whiles one out every twenty would pay a maximum of GHS 500. Whereas, in the case of respondents' willing to accept compensation for conservation of tree life, one out of every ten respondents were willing to accept a minimum of GHS 100 whiles three out of every 10 respondents would accept a minimum of GHS 500. This confirms the findings by Carson et al. (1995) who indicates that individuals are more willing to accept higher compensation than will be willing to pay.

Notwithstanding these positive perceptions, the study also identified some misconceptions. Some residents saw tree planting as the sole responsibility of the government. Others also perceived it as a means to acquire wood as fuel for cooking. Again, observation from estate development in Abokobi seems to suggest that they have no value for trees since no efforts were made for tree replacement. The Municipal Environmental Health Officer had these to say:

"People think tree planting is the responsibility of the Forestry Department. People are felling trees without replacing them" (Municipal Environmental Health Officer)

\section{Health Officer)}

"When you plant trees, people think you are giving them firewood" (Municipal Environmental

"What everybody is thinking is that the place is becoming nice, we are having beautiful estates. This place is no more a village and a lot of people and business around the place" (Municipal Environmental

\section{Health Officer)}

\subsubsection{Prospects and Challenges}

Another objective this study sought to investigate was the prospects and challenges of tree life in Abokobi. Findings from the study suggests that, apart from the chief, most of the respondents presented a gloomy picture of the prospects of tree life. Perhaps this may be attributed to the large-scale real-estate activities and individual housing activities. The chief on the other hand, had hopes and saw further prospects with regards to the tree life of the study area. He asserted that afforestation was the means of improving the tree life existence of the area with the help of a firm from California. He noted thus:

"What we are going to do if God permits and I know He will permit and we get our land back, all the buildings we will pull them down and plant our trees. Otherwise, we will plant our mango trees in the line we want to, and the buildings will stay there" (Chief of Abokobi) 
Concerning the challenges facing tree life in Abokobi, the main issues raised by the key informants were the form of land tenure systems of the study area and weak government institutions. Other challenges also included urbanisation, disputes over the ownership of land between Abokobi and Brekusu Traditional Authorities. Some of their comments on the challenges of tree life in Abokobi are captured as follows:

"urbanisation is the prime cause of tree loss here. People want to survive; people want land to build houses, and we don't plan our development. Improper urbanisation, uncontrolled urbanisation" (Municipal Deputy Director of Agriculture)

"The building codes, if you go through carefully are more focused on structural efficiencies and nothing about tree life" (Municipal Environmental Health Officer)

"Land ownership is the biggest problem; the assembly must have a land use plan but since the assembly does not own the lands here, there's little we can do. There are areas earmarked for development work, but the government has not been able to acquire it" (Municipal Environmental Health Officer)

\subsubsection{Institutional Arrangements}

Notwithstanding the numerous challenges which pose a threat to tree life in Abokobi, there are certain institutional arrangements which have been made to help salvage the loss of tree life in the community. One can deduce that despite these institutional arrangements, the loss of tree life in Abokobi has escalated to an uncontrollable level. A buffer zone or land was reserved by the Local Government Institute in Abokobi, but this has been depleted by the activities of estate developers. It is also mandatory for anyone who cuts down a tree to seek permit from the Forestry Commission, but this does not happen in practice. Some provisions have been made in the by-laws for tree planting and replacement but lacks implementation. Finally, GEMA has embarked on some tree planting exercises and has met with the traditional authorities and sensitized them on tree planting but all to no avail. Despite these arrangements, tree life is under serious threat in the Abokobi community. Residents in the community were not aware of most of the institutions mentioned above. Most of these institutional arrangements rest in the offices of the assembly.

Some of key informants had these to say about the institutional arrangements made to preserve tree life in Abokobi:

“Building permit will not be given to build on green areas" (Municipal Town \& Country Director)

"Forestry Commission is in charge of preserving the forest and as such if you want to cut down trees, if you want to do anything, they are supposed to do that one" (Municipal Deputy Planning Officer)

"In 2015, the assembly met with the chiefs and families around and advised them on how to sell their lands and when they do so the assembly should have the scheme of the portion of land they have sold to the people so that we can also use it to plan for the municipality" (Municipal Works Engineer)

"The by-law has in it that if anyone cuts the tree, it must be replaced but we are not able to enforce it. The environmental officers, they are to ensure this" (Municipal Deputy Planning Officer)

\section{Conclusion}

This paper examined the challenges and prospects of tree life in Abokobi in the Ga East Municipality. The study found out that between the base year of 2005 to 2017, the study area had experienced continuous depletion of vegetative cover including tree life. This has serious implications on human life and the ecosystem. The study also revealed divergent perception on the role of tree life among key informants and residents of the study area. Again, findings from this paper indicates the presence of existing policies vis-à-vis institutional arrangements governing tree life in the study area. The paper therefore recommends a participatory planning process as an ideal development pathway for the study area, an all-inclusive review of the land tenure system and the augmentation of institutional coordination in enforcing building protocols.

\section{References}

Arouri, M.E.H., Youssef, A.B., Nguyen-Viet, C. and Soucat, A., 2014. Effects of urbanization on economic growth and human capital formation in Africa.

Arouri, M.E.H., Youssef, A.B., Nguyen-Viet, C. and Soucat, A., 2014. Effects of urbanization on economic growth and human capital formation in Africa. 
Carson, R.T., Wright, J., Carson, N., Alberini, A. and Flores, N., 1995. A bibliography of contingent valuation papers and studies. NRDA: La Jolla, CA.

Centre for Social Development, Humanitarian Affairs (United Nations), UNICEF., United Nations Population Fund, United Nations Development Fund for Women, United Nations. Statistical Division and World Health Organization., 2010. The World's Women Trends and Statistics. United Nations.

Cui, L., and Shi, J., 2012. Urbanisation and its environmental effects in Shanghai, China. Urban Climate, 2,1-15.

Dei, G.J., 1992. A forest beyond the trees: Tree cutting in rural Ghana. Human Ecology, 20(1), pp.57-88.

Dwyer, J. F., Schroeder, H. W., and Gobster, P. H., 1991. The significance of urban trees and forests: toward a deeper understanding of values.

Ghana Statistical Service, 2010 Population and Housing Census.

Ghana Statistical Service, Population and Housing Census, 2014.

Grant and Yankson 2003, City Profile Accra Elsevier Volume 20, Issue 1, February 2003, Pages 65-74.

Heusinkvelt, B., 2016. Studying the Effect of Urbanisation on Tree Growth Surrounding Streams in Lincoln. University of Nebraska. Undergraduate Thesis.

Jabik, B.B. and Bawakyillenuo, S., 2016. Green entrepreneurship for sustainable development in Ghana: a review. GHANA SOCIAL SCIENCE, 13(2), p.96.

Kim, Y.H., Baik, J.J., 2005. Spatial and temporal structure of the urban heat island in Seoul. Journal of Applied Meteorology 44, 591-605.

Mol, A.P., 1995. The refinement of production: Ecological modernization theory and the Dutch chemical industry. Utrecht: Jan van Arkel Books.

Mougeot, L.J., 2006. Growing better cities: Urban agriculture for sustainable development. IDRC.

Nowak, D. J., and Crane, D. E., 2002. Carbon storage and sequestration by Tree lives in the USA. Environmental pollution, 116(3), 381-389.

Richards, P., and VanWey, L., 2015. Where deforestation leads to urbanisation: how resource extraction is leading to urban growth in the Brazilian Amazon. Annals of the Association of American Geographers, 105(4), 806-823.

World Bank, 2013. Center for liveable cities, Singapore. Urbanisation and Development: Achievements, Challenges and Options" Jointly presented by the Center for Liveable Cities and the World Bank Theatrette, Monetary Authority of Singapore 6 May 2013. 